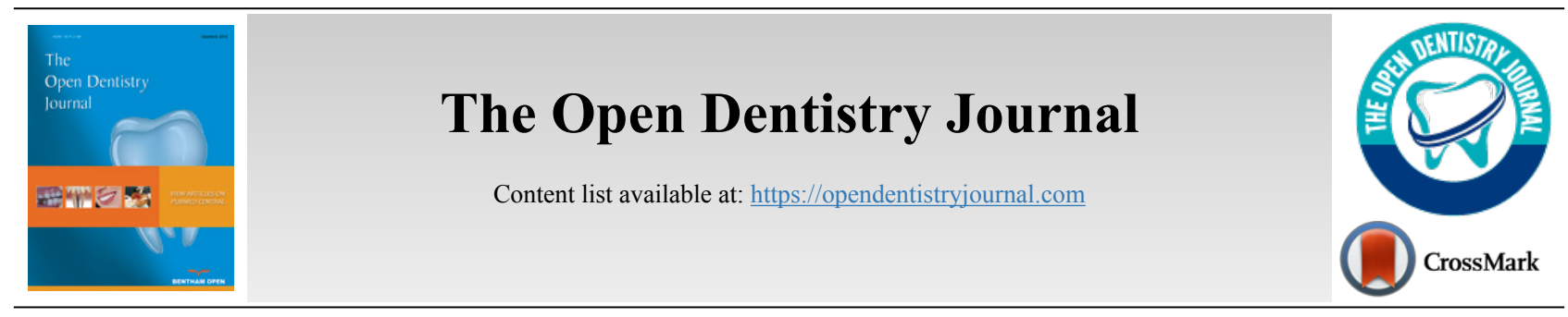

RESEARCH ARTICLE

\title{
Fracture Resistance of Three Post Types in the Restoration of Anterior Primary
} Teeth

\author{
Fatemeh Kadkhodaei $^{1(\mathrm{D})}$, Majid Mehran ${ }^{2(\mathrm{D})}$ Roza Haghgoo $^{3(\mathrm{D})}$ and Mehrshad Zareiyan ${ }^{3, *(D)}$ \\ ${ }^{\text {I} P r i v a t e ~ P r a c t i c e, ~ T e h r a n, ~ I r a n . ~}$ \\ ${ }^{2}$ Department of Pediatric Dentistry, Faculty of Dentistry, Shahed University, Tehran, Iran. \\ ${ }^{3}$ Department of Pediatric Dentistry, Faculty of Dentistry, Shahed University, Tehran, Iran.
}

\begin{abstract}
:
Background:

Extensive restorative treatments of anterior primary teeth are challenging in pediatric dentistry.

Objective:

This study aimed to compare the fracture resistance of three post types for restoring the anterior primary teeth.

Methods:

This in-vitro study was carried out on 90 extracted maxillary anterior primary teeth with intact roots. They were randomly allocated into six groups to be restored with conventional composite resin post, X-tra fill composite resin post, Tetric N Ceram composite resin post, prefabricated glass fiber post with conventional composite build-up, prefabricated glass fiber post with X-tra fill composite build-up, and prefabricated glass fiber post with Tetric N Ceram composite build up. The samples were polished and placed in acrylic resin blocks with $1 \mathrm{~mm}$ of part of cervical root being out, thermocycled $(\times 5000)$ and tested for fracture resistance. Intra-class correlation test, Kruskal-Wallis test and one-way ANOVA were used for statistical analyses $(\alpha=0.05)$.

Results:

The mean fracture resistance was significantly different among the six groups. It was the highest in prefabricated glass fiber post with conventional composite build-up $(418.64 \mathrm{~N})$, prefabricated glass fiber post with X-tra fill composite build-up $(403.63 \mathrm{~N})$ and prefabricated glass fiber post with Tetric N Ceram composite build up $(361.63 \mathrm{~N})$; and the lowest in Tetric N Ceram group $(280.65 \mathrm{~N})$. The groups were significantly different concerning the fracture strength and fracture state.

\section{Conclusion:}

Since the anterior teeth restored with prefabricated glass fiber posts were far more fracture resistant, and prefabricated glass fiber posts can be promisingly used for the restoration of anterior primary teeth.
\end{abstract}

Keywords: Anterior teeth, Composite, Fracture resistance, Fracture strength, Glass fiber, Primary teeth.

\begin{tabular}{|l|c|c|c|}
\hline Article History & Received: February 20, 2020 & Revised: May 10, 2020 & Accepted: May 17, 2020 \\
\hline
\end{tabular}

\section{INTRODUCTION}

Dental caries is the most prevalent chronic childhood disease [1]. Early childhood caries has a clinically distinguished pattern in very young children. The maxillary central and lateral incisors as well as the first primary molars of

\footnotetext{
* Address correspondence to this author at the Department of Pediatric Dentistry, Faculty of Dentistry, Shahed University, Tehran, Iran,

Tel: +98-9379235457; E-mail: mehrshad.zareiyan@yahoo.com
}

both the mandible and maxilla are the teeth most engaged in dental caries [2]. Clinicians generally find it challenging to restore severely decayed maxillary primary incisors [3]. Extraction was traditionally the only solution for such teeth. Premature loss of teeth may cause abnormal position of the tongue, speech disorders, mastication problems, psychological problems because of esthetic issues, decrease of the bite force, reduction of the vertical height of the face and mouth breathing habits $[3-6]$. 
Restoration of anterior primary teeth has always been a great challenge in pediatric dentistry due to various reasons such as small crown size, large pulp chamber, and the pediatric patient's age. The low strength of restorations and the subsequent fractures are usually related to the improper tooth structure [6]. Concerning the anterior teeth, it is not only important to preserve the tooth structure and reconstruct the primary form of the teeth, but also to consider the aesthetics and use of composite resins. Meanwhile, because of structural differences between primary and permanent teeth like less available dentin for bonding, composite restorations induce some issues for the primary teeth [7].

The longevity of composite crowns highly depends on the intracanal retention in severely damaged pulpotomized incisors [8]. Many post types can be used in pediatric dentistry such as prefabricated posts [9], orthodontic wires in "a", "y", composite resin posts, fiber posts and biologic posts [9 - 11]. The recently marketed non-metallic prefabricated posts, namely fiber-based ones, are considered as a suitable substitute for their metallic counterpart. They have excellent mechanical features like fracture toughness, compressive strength, loadbearing capacity, flexural strength, fatigue resistance, fracture strength and, biocompatibility with different core materials [12, 13]. The fiber-reinforced composites have clinical applications such as splinting mobile teeth, direct construction of posts and cores, and reinforcement elements of dentures or pontics [14]. Current fiber-based posts are made of carbon or silica fibers covered by a polymer resin matrix. The translucent and toothcolored silica-fiber posts are also known as glass-fiber and quartz-fiber [15]. Both prefabricated and customized forms of composite posts reinforced by fibers are available [16].

Despite the numerous clinical studies on the restorative treatment of primary teeth $[9,11]$, information is still lacking about the physical and mechanical features of post-supported restorations, especially fiber posts. The present in-vitro study aimed to assess and compare the fracture resistance of three types of post including traditional composite resin, bulk-fill composite resin, and prefabricated glass fiber.

\section{MATERIALS AND METHODS}

This experimental in-vitro study was conducted on 90 extracted primary maxillary anterior teeth with intact roots. The sample size was calculated by using STATA software(Stata Corp., Texas, USA) as $\mathrm{n}=15$ per group $(\alpha=0.05$ and power $=80 \%$ )based on previous similar studies $[17,18]$. The samples were stored in $0.5 \%$ chloramine-T solution for 1 week to be cleansed [19], and then, in distilled water at $4{ }^{\circ} \mathrm{C}$ till used. By using a diamond bur (Jota, Switzerland)and a highspeed handpiece (PanaAir FX, NSK, Japan), horizontal cuts were made $1 \mathrm{~mm}$ above the cementoenamel junction (Fig. 1), and the root canals were prepared to size 45 by using K-files (Mani Inc.; Japan) $1 \mathrm{~mm}$ short of the apex. The root canals were dried by paper points and filled with calcium hydroxide paste with iodoform (Metapex; Meta Biomed Co. Ltd, Korea) (Fig. 2). Having removed $4 \mathrm{~mm}$ of the paste from the coronal part of canals, $1 \mathrm{~mm}$ light-cured liner (Lime-Lite light cure cavity liner; Pulpdent Co, MA, USA)was used to cover the orifices and cured for 40s (seconds) by light-emitting diode (Radii; SDI Co., Australia), leaving $3 \mathrm{~mm}$ space for posts.

The teeth were randomly classified into six groups through blocked randomization by using blocks of $2 \times 2 \times 2.5 \mathrm{~cm}$ and 1 specimen per block. The samples were coded based on the employed material and number of samples. To consider the effect of the bonded surface on the fracture resistance,cone beam computed tomography (NewTom, VGI, Verona, Italy) was done and the bonded cross-sectional area of each sample was calculated by using On-Demand software (On-demand3D; version 1.0.10.6388, Cybermed, Korea).

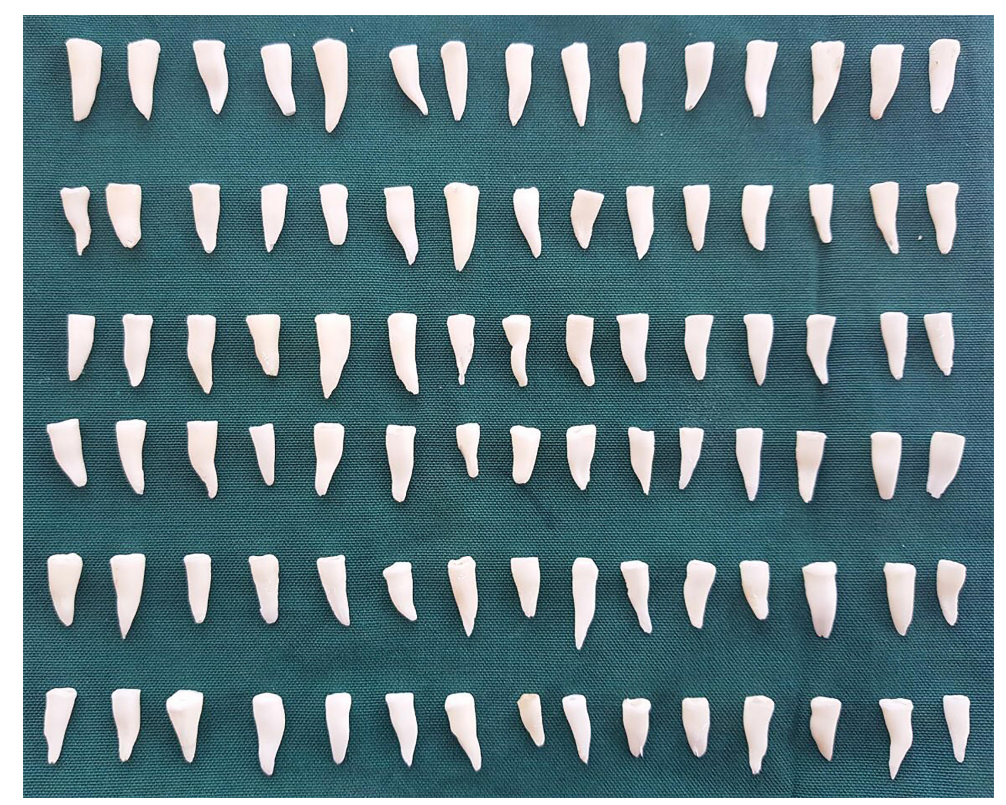

Fig. (1). The specimens after being cut $1 \mathrm{~mm}$ above the cementoenamel junction. 


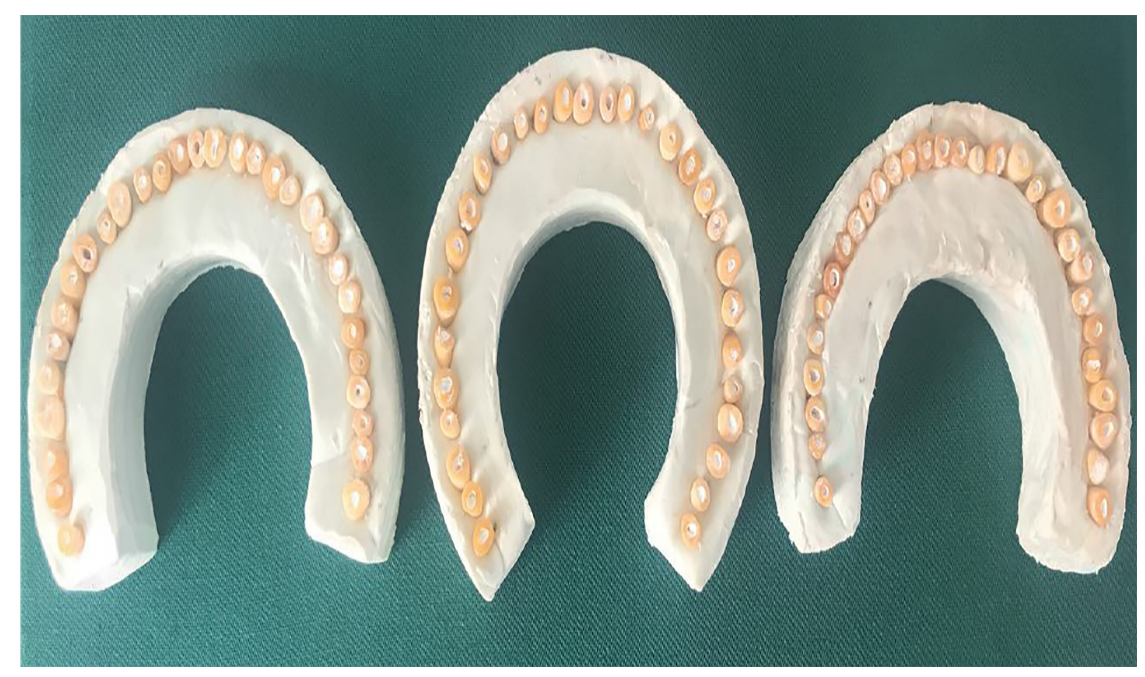

Fig. (2). The specimens after obturation with Metapex.

\subsection{Preparing Specimens}

For three groups of samples, acid (Scotchbond Etchant, 3M ESPE, MN, USA) was applied on the rinsed and dried tooth and the intra-canal area for $15 \mathrm{~s}$ [19]. Then, the acid was rinsed for $10 \mathrm{~s}$ and dried, while the dentin areas were still wet. Two covers of the cured bonding agent (Adper Single Bond, 3M ESPE, MN, USA)were used on the etched surface, dispersed uniformly for $2-5 \mathrm{~s}$ by a compressed air blast, and then, cured (Radii,SDI Co,Australia) at $1200 \mathrm{~m} \mathrm{~W} / \mathrm{cm}^{2}$ for $10 \mathrm{~s}$. To restore the crown of 4-mm height, one of the conventional composite resin post ( 2 layers of $2 \mathrm{~mm}$ height, each cured for $20 \mathrm{~s}$ ) (Z 250,3M ESPE,USA), X-tra fill composite resin post (one layer of 4-mm height) (X-tra fill composite,Voco, USA), or Tetric N Ceram composite resin post (one layer of 4-mm height) (Ivoclar Vivadent, Germany) was incrementally pressed into the canal and cured for $20 \mathrm{~s}$.

In the three other groups, a diamond bur on a high-speed handpiece under copious water-coolant was used to cut sections of $5 \times 1.1 \mathrm{~mm}$ (lengths $\times$ diameter) of prefabricated glass fiber post (Reforpost, Angelus, Brazil) with conventional composite build-up, prefabricated glass fiber post with X-tra Fill composite build-up (Z 250,3M ESPE,USA), or prefabricated glass fiber post with Tetric N Ceram composite build-up (Ivoclar Vivadent, Germany). The sections were cleaned with alcohol. The post space was irrigated and lightly dried. Both the double-cured cement and the post were placed in the canal. The excess cement was removed and the remnant was cured for 40s. Restoration of the 4-mm-high crown with composite was done just as in the first group. In all groups, the post length was $3 \mathrm{~mm}$ and the crown height was $4 \mathrm{~mm}$. Having restored the samples, polishing was done by using composite polishing bur(Kerr,CA,USA) and high-speed handpiece under water-coolant (Fig. 3).

\subsection{Fracture Resistance Test}

The restored teeth were placed in acrylic resin blocks with almost 1 millimeter of the root cervical part remaining out of the acrylic resin and thermocycled between water baths $\left(5000 \times 5{ }^{\circ} \mathrm{C}\right.$ and $55^{\circ} \mathrm{C}$ with a 30 -second dwell time per bath). To measure the fracture resistance, the specimens were fixed by using a special fixture. The Universal Testing Machine (QM series, Zwick/Roell, Germany) applied an increasingly growing load at a crosshead speed of $0.5 \mathrm{~mm} / \mathrm{min}$ and an angle of 148 degree $[12,15,16,20]$ along the long axis of the primary incisors on the mid-palatal surface until failure. Although this angle is 135 degree for the permanent teeth, the force in this study was applied at 148 degree to simulate the occlusal forces on the maxillary incisors in class I occlusion while the primary incisors are straight $[20,21]$. The fracture strength (stress) was calculated by dividing the fracture resistance values by the bonded cross-sectional area $\left(\mathrm{N} / \mathrm{mm}^{2}\right)$. The fractures occurring above the cementoenamel junction were considered as restorable; and those below the cementoenamel junction were considered as unrestorable fractures.

Data were analyzed by using the SPSS software (version 20; SPSS Inc., Chicago, IL, USA) through one-way ANOVA, intraclass correlation test (ICC), and Kruskal-Wallis test $(\alpha=0.05)$.

\section{RESULTS}

The mean fracture resistance was $296.57 \mathrm{~N}$ in the conventional composite resin post, $282.08 \mathrm{~N}$ in X-tra fill composite resin post, $280.65 \mathrm{~N}$ in Tetric $\mathrm{N}$ Ceram composite resin post, $418.64 \mathrm{~N}$ in prefabricated glass fiber post with conventional composite build-up, $403.63 \mathrm{~N}$ in prefabricated glass fiber post with X-tra fill composite build-up, and 361.72 $\mathrm{N}$ in prefabricated glass fiber post with Tetric $\mathrm{N}$ Ceram composite build-up (Table 1, Fig. 4). The fracture resistance was found to be significantly higher in prefabricated glass fiber post groups $(\mathrm{P}<0.05)$. Table 2 displays the mean and standard deviation $( \pm \mathrm{SD})$ of fracture strength in the six study groups $\left(\mathrm{N} / \mathrm{mm}^{2}\right)$. The highest fracture strength value was seen in prefabricated glass fiber post with conventional composite build-up group followed by prefabricated glass fiber post with $\mathrm{X}$-tra fill composite build-up group. The lowest fracture strength value was seen in X-tra fill composite resin post. Statistically significant differences were observed among the 


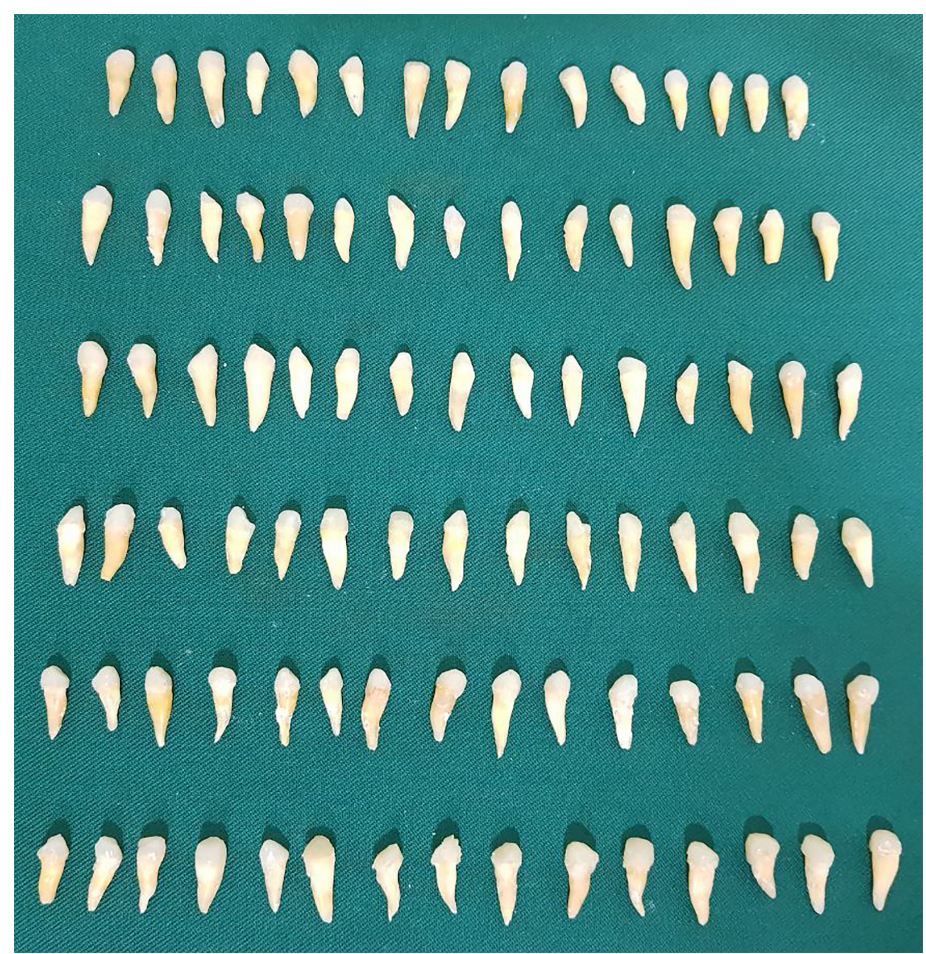

Fig. (3). The specimens after polishing composite.

Table 1. Mean \pm standard deviation of the fracture resistance $(\mathrm{N})$.

\begin{tabular}{|c|c|}
\hline Groups & Fracture Resistance \\
\hline Z250 & $296.58 \pm 98.35$ \\
\hline X-tra fill & $282.08 \pm 53.19$ \\
\hline Tetric N Ceram & $280.65 \pm 73.26$ \\
\hline Post + Z250 & $418.65 \pm 114.98$ \\
\hline Post + X-tra fill & $403.64 \pm 101.03$ \\
\hline Post + Tetric N Ceram & $361.72 \pm 132.26$ \\
\hline
\end{tabular}

Table 2. Mean \pm standard deviation of the fracture strength $\left(\mathrm{N} / \mathrm{mm}^{2}\right)$.

\begin{tabular}{|c|c|}
\hline Groups & Fracture Strength \\
\hline Z250 & $11.5 \pm 2.08$ \\
\hline X-tra fill & $10.53 \pm 0.72$ \\
\hline Tetric N Ceram & $11.15 \pm 2.02$ \\
\hline Post + Z250 & $15.05 \pm 2.88$ \\
\hline Post + X-tra fill & $13.75 \pm 2.15$ \\
\hline Post + Tetric N Ceram & $13.2 \pm 3.04$ \\
\hline
\end{tabular}




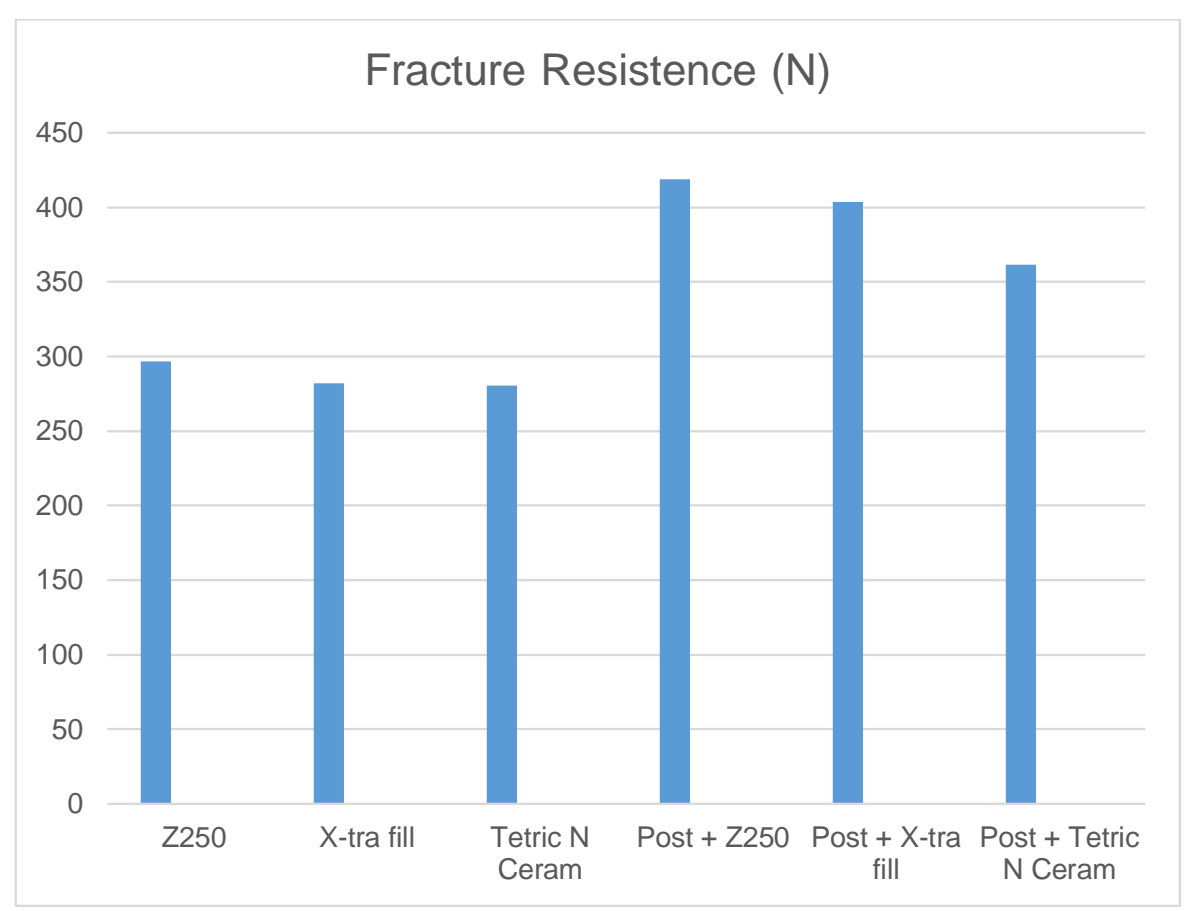

Fig. (4). The mean fracture resistance of the study groups (N).

\section{Fracture Strength $\left(\mathrm{N} / \mathrm{mm}^{2}\right)$}

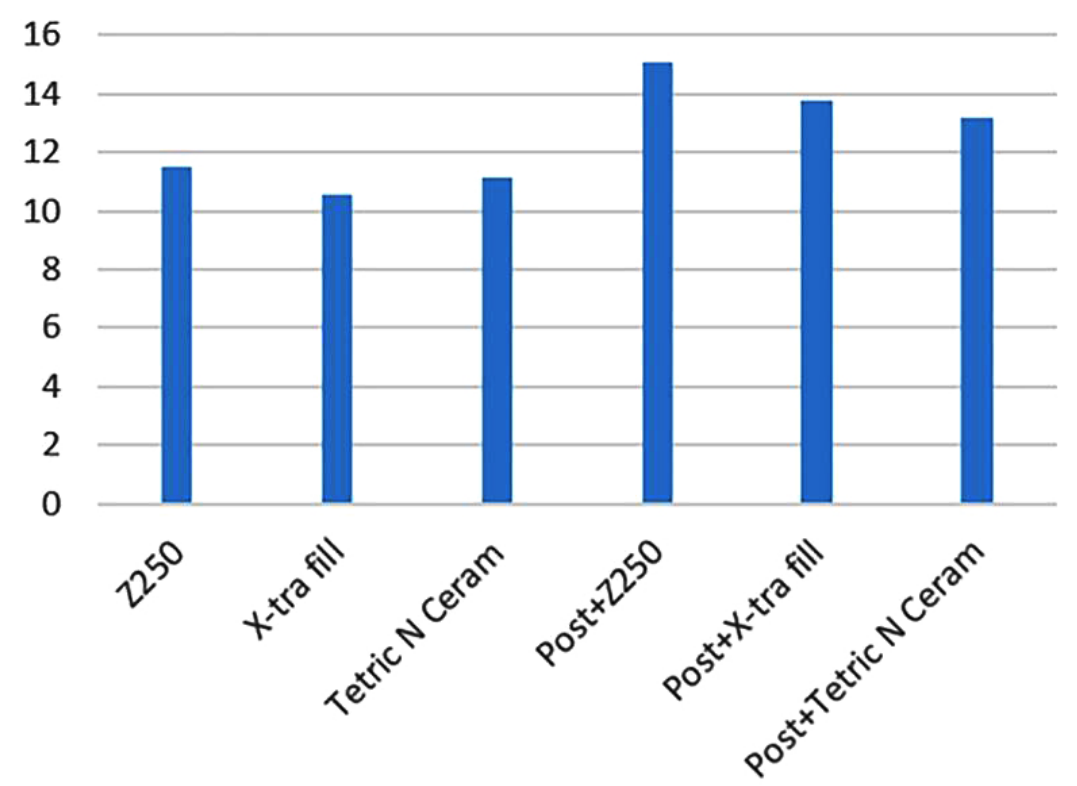

Fig. (5). The mean fracture strength of the study groups $\left(\mathrm{N} / \mathrm{mm}^{2}\right)$.

Table 3. Mean \pm standard deviation of the bonded surface area $\left(\mathrm{mm}^{2}\right)$.

\begin{tabular}{|c|c|}
\hline Groups & Bonded Surface Area \\
\hline Z250 & $25.4 \pm 5.34$ \\
\hline X-tra fill & $26.86 \pm 5.3$ \\
\hline Tetric N Ceram & $24.79 \pm 2.58$ \\
\hline Post + Z250 & $27.54 \pm 4.59$ \\
\hline
\end{tabular}


(Table $\square$ ) contd.....

\begin{tabular}{|c|c|}
\hline Groups & Bonded Surface Area \\
\hline Post + X-tra fill & $28.95 \pm 3.20$ \\
\hline Post + Tetric N Ceram & $26.79 \pm 4.05$ \\
\hline
\end{tabular}

\section{Bonded Surface area $\left(\mathrm{mm}^{2}\right)$}

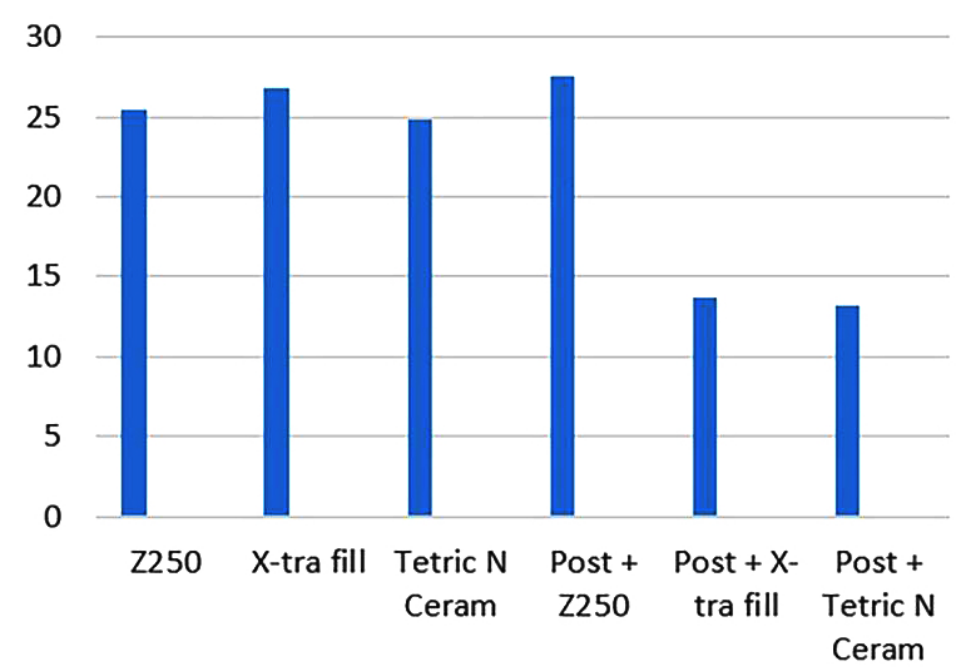

Fig. (6). The mean bonded surface area of the study groups $\left(\mathrm{mm}^{2}\right)$.

\section{DISCUSSION}

Fracture resistance is among the most determining properties of restoration materials and one of the significant contributors to the restoration longevity [12]. The findings of the present study revealed the highest and lowest fracture resistance in the samples restored with prefabricated glass fiber post and conventional composite build-up and those restored with Tetric N Ceram composite resin post, respectively. The difference between the two groups could be due to the greater bond strength and comparable modulus of elasticity to dentin in samples restored with fiber post [22].

An important feature to be considered is the effect of polymerization efficacy on the mechanical properties of composite resins and post. Many factors such as polymerization type, light-curing time, depth of cut and surface pretreatment can affect the polymerization. The nanofillers of fiber-reinforced composites result in higher flexural strength values compared with the conventional types after oven postcuring; however, it was not significantly different from when hand light-curing was done per se. Postcuring oven polymerization of light-cured composites was reported to improve the wear resistance and hardness [23].

Polymerization is carried out at different light-exposure durations in intracanal root restoration with composite resin and translucent fiber post. It was reported that polymerization duration would not affect the bond strength of translucent fiber posts to experimentally weakened radicular dentin [24]. Yet, sufficient polymerization of light-cured resin composites imperatively affects the success of restoration. The 2-mm incremental technique used for the conventional composite resin would result in well polymerization; however, it is rather time-consuming. The problem is managed by using bulk-fill resin composites that can be cured in a thickness of $4 \mathrm{~mm}$ or even more. Polymerization of $4 \mathrm{~mm}$-thick for bulk-fill composites (particularly $\mathrm{x}$-tra fill and GrandioSO $\mathrm{x}$-tra) creates a sufficient degree of conversion. Concerning the correlation between the depth of cure and degree of conversion of resin composite by micro-hardness, no significant difference was noted in the hardness ratio between bulk fill composite and traditional resin base composite [25]. The Er,Cr:YSGG Laser irradiation changed features of dentin surface and enhanced the bond strength of resin cement and fiber post to dentin [26].

Given the limited number of studies about the primary teeth fracture resistance, the present findings could not be compared with those of the previous ones. In line with the present study, Hedge et al. compared the fracture strength of three posts (cast post, glass fiber post, and quartz fiber post) in the permanent teeth. They observed that although the mean value of the fracture strength in quartz fiber post $(480.9 \mathrm{~N})$ was higher than that in glass fiber post group $(432.2 \mathrm{~N})$, the difference was not significantly different between the two groups [27]. The greater fracture strength reported by Hegdemight be due to the larger diameter of the teeth and the enamel area available for bond, lack of thermocycling, higher length of the post, and application of different types of cement.

Sharaf [28] reported significantly higher fracture resistance when using the fiber post $(230.6 \mathrm{~N})$ compared with the composite post $(277.9 \mathrm{~N})$. These values were lower than those obtained in the present study probably due to the differences in the post, cement, and composite resin. Ambica et al. [29] 
evaluated the fracture resistance in the permanent teeth by four methods following restoration including no using post, carbon fiber post, glass fiber post, and dentin post. The mean fracture resistance was $603.44 \mathrm{~N}$ in the glass fiber post group because of the larger diameter of the tooth and posts. Nor did they assessed the effect of thermocycling on different posts, cement, and specimens.

In an in-vivo study, Eshghi et al. [1] detected no significant change in the retention of different techniques after 12 months follow-up including fiber post (90\%), composite post (98\%) and reverse metallic post $(100 \%)$. This was in line with the results of the studies by Sharaf [28] and Judd et al. [30], which reported $100 \%$ success for the composite posts and fiber posts.

According to the literature, the tooth diameter highly affects the fracture resistance [31]. To keep it minimum, researchers measure and adapt the mesiodistal and buccopalatal width of samples in the cementoenamel junction area in different groups [31, 32]. In the present study, the fracture strength of the specimen was evaluated and compared through precise calculation of the cross-sectional area. This was one of the strengths of this study, as this effect was not considered in other studies. Despite using the term "fracture strength", other studies have calculated the fracture resistance based on definitions. Sharaf's clinical study reported that using fiber posts in severely damaged anterior primary teeth was a satisfactory method. After 1 year, only 2 out of 30 teeth were extracted due to either luxation or failed pulp therapy. It was also reported that fiber posts significantly enhanced the teeth fracture resistance, and composite posts significantly increased the fracture resistance compared to using no post [28].

Gujjar and Indushekar [33] compared the retentive strength of three different posts including composite post, orthodontic wire $\gamma$, and glass fiber post in the primary incisors. They observed the highest tensile strength in the glass fiber post group and the lowest in the composite post group, being significantly different. The higher retentive strength of fiber posts was attributed to the stronger post-cement bond and better light transmission through these posts, which can enhance the polymerization of cement in the apical area.

The present study classified the fracture mode as restorable (above the cementoenamel junction) and unrestorable (below the cementoenamel junction). According to Varvara et al.'s study [31] on the permanent central teeth, the cracks above the bone margin in the permanent central incisors were restorable, and those below the margin were unrestorable. Another study reported the incisal third of the root as restorable [34]. However, due to the infrequency of the crown lengthening surgery in pediatric dentistry, the fractures above the cementoenamel junction are considered as restorable.

In this study, the frequency of unrestorable fracture mode was $30 \%$ in the composite groups and $16 \%$ in fiber post groups. Although the difference was not significant, it showed that using the fiber post decreased the frequency of unrestorable fractures. It was consistent with the results reported by Sherfudhin et al. [32]. In the study by Hegde et al. [27], $100 \%$ of the glass fiber and quartz fiber posts showed restorable fractures; whereas, only $13.3 \%$ of the cast posts had restorable fractures. Pithan [35] found that the fracture mode was adhesive in $80 \%$ of glass fiber posts and $47 \%$ of composite posts, and these values were respectively $100 \%$ and $20 \%$ in Gujjar's study [33]. These authors attributed the adhesive fracture to the bond failure between the cement and root canal. Moreover, they used resin composite for post cementation. Hence, in the present study, the fiber posts were cemented with dual-cured resin cement with the prominent advantages of excellent bond strength, increased working time and reduced chairside time, great mechanical properties, and a high degree of conversion $[21,36]$.

In the current study, the length of the post was $3 \mathrm{~mm} \mathrm{(1/3}$ of the canal length), which is the proper length of the post in the primary teeth and does not interfere with the eruption of permanent teeth $[6,9]$. A strong point of this study was the thermocycling of samples between $5{ }^{\circ} \mathrm{C}$ and $55{ }^{\circ} \mathrm{C}$ for better simulation of the oral environment. Since these cycles enhance the restoration strength and durability in the oral cavity [37], they not only reduce the fracture resistance and increase the accuracy of the results but also resemble the clinical conditions.

According to a study on 3-6-year-old children, the maximum bite force at the first and second molars and central incisors ranged from 12.61 to $353.6 \mathrm{~N}$ (mean 196.6 N) [38]. Another study reported this value to be $176 \mathrm{~N}$ in the early primary stage and $240 \mathrm{~N}$ in the late primary stage [39]. These forces are significantly higher in the oral environment under physiological conditions [40] and they can influence the employed materials through constant stresses. In the present study, fracture resistance ranged between $280.65 \mathrm{~N}$ and 418.65 $\mathrm{N}$, indicating it to be clinically acceptable in all groups.

\section{CONCLUSION}

The results of this study revealed significantly different fracture strength, fracture resistance, and fracture mode in resin composite and glass fiber post groups. Considering higher fracture resistance of the anterior teeth restored with prefabricated glass fiber post, it can be concluded that prefabricated glass fiber posts can be promisingly used for restoration of anterior primary teeth.

\section{ETHICS APPROVAL AND CONSENT TO PARTI- CIPATE}

This study was approved by the Ethics Committee of Shahed University, Iran (IR.SHAHED.REC.1398.080).

\section{HUMAN AND ANIMAL RIGHTS}

Not applicable

\section{CONSENT FOR PUBLICATION}

Not applicable.

\section{AVAILABILITY OF DATA AND MATERIALS}

The data sets analyzed during the current study are available from the corresponding author [M.Z.] upon reasonable request. 


\section{FUNDING}

None.

\section{CONFLICT OF INTEREST}

The authors declare no conflict of interest.

\section{ACKNOWLEDGEMENTS}

The authors would like to express deep appreciation to Ms. Farzaneh Rasouli for proofreading, editing, and improving the English structure of this manuscript.

\section{REFERENCES}

[1] Eshghi A, Kowsari-Isfahan R, Khoroushi M. Evaluation of three restorative techniques for primary anterior teeth with extensive carious lesions: a 1-year clinical study. J Dent Child (Chic) 2013; 80(2): 80-7. [PMID: 24011296]

[2] Benitez C, O'Sullivan D, Tinanoff N. Effect of a preventive approach for the treatment of nursing bottle caries. ASDC J Dent Child 1994; 61(1): 46-9.

[PMID: 8182198]

[3] Motisuki C, Santos-Pinto L, Giro EMA. Restoration of severely decayed primary incisors using indirect composite resin restoration technique. Int J Paediatr Dent 2005; 15(4): 282-6.

[http://dx.doi.org/10.1111/j.1365-263X.2005.00645.x] [PMID: 16011787]

[4] Dean JA, Avery DR, McDonald RE. Mcdonald and avery's dentistry for the child and adolescent. Elsevier Health Sciences 2011.

[5] Malakar S, Tripathi S, Rahat A. Analysis of fracture resistance of different posts in restoration of severely damaged primary anterior teeth: An in vitro study. International Journal of Research and Analytical Reviews 2019; 6: 451-69.

[6] Verma L, Passi S. Glass fibre-reinforced composite post and core used in decayed primary anterior teeth: a case report. Case Rep Dent 2011; 2011864254

[http://dx.doi.org/10.1155/2011/864254] [PMID: 22567447]

[7] Uekusa S, Yamaguchi K, Miyazaki M, Tsubota K, Kurokawa H, Hosoya Y. Bonding efficacy of single-step self-etch systems to sound primary and permanent tooth dentin. Oper Dent 2006; 31(5): 569-76. [http://dx.doi.org/10.2341/05-102] [PMID: 17024945]

[8] Pollard MA, Curzon JA, Fenlon WL. Restoration of decayed primary incisors using strip crowns. Dent Update 1991; 18(4): 150-2. [PMID: 1884866]

[9] Viera CL, Ribeiro CC. Polyethylene fiber tape used as a post and core in decayed primary anterior teeth: a treatment option. J Clin Pediatr Dent 2001; 26(1): 1-4.

[http://dx.doi.org/10.17796/jcpd.26.1.p75643n238120x62] [PMID: 11688805]

[10] Mendes FM, De Benedetto MS, del Conte Zardetto CG, Wanderley MT, Correa MS. Resin composite restoration in primary anterior teeth using short-post technique and strip crowns: a case report. Quintessence Int 2004; 35(9): 689-92. [PMID: 15470991]

[11] Ramires-Romito ACD, Wanderley MT, Oliveira MDM, Imparato JCP, Corrêa MSNP. Biologic restoration of primary anterior teeth. Quintessence Int 2000; 31(6): 405-11.

[PMID: 11203957]

[12] Abd E, Sonia E-S, Omar E-M, Hashem R. Clinical and laboratory evaluation of two different types of the post system in restoring destructed primary anterior teeth. Egypt Dent J 2005; 51: 1159-77.

[13] Palepwad AB, Kulkarni RS. In vitro fracture resistance of zirconia, glass-fiber, and cast metal posts with different lengths. J Indian Prosthodont Soc 2020; 20: 202-7.

[http://dx.doi.org/10.4103/jips.jips_321_19]

[14] Scribante A, Vallittu PK, Özcan M. Fiber-reinforced composites for dental applications. BioMed Res Int 2018; 20184734986 [http://dx.doi.org/10.1155/2018/4734986] [PMID: 30515400]

[15] Lamichhane A, Xu C, Zhang FQ. Dental fiber-post resin base material: a review. J Adv Prosthodont 2014; 6(1): 60-5. [http://dx.doi.org/10.4047/jap.2014.6.1.60] [PMID: 24605208]

[16] Singh A, Logani A, Shah N. An ex vivo comparative study on the retention of custom and prefabricated posts. J Conserv Dent 2012; 15(2): 183-6. [http://dx.doi.org/10.4103/0972-0707.94583] [PMID: 22557821]

[17] Mosharrafian S, Sharifi Z. Comparison of push-out bond strength of two bulk-fill and one conventional composite to intracanal dentin in severely damaged primary anterior teeth. J Dent (Tehran) 2016; 13(3): 207-14.

[PMID: 28392818]

[18] Nilavarasan N, Hemalatha R, Vijayakumar R, Hariharan VS. Comparison of compressive strength among three different intracanal post materials in primary anterior teeth: An in vitro study. Eur J Dent 2016; 10(4): 464-8.

[http://dx.doi.org/10.4103/1305-7456.195181] [PMID: 28042259]

[19] Seraj B, Ghadimi S, Estaki Z, Fatemi M. Fracture resistance of three different posts in restoration of severely damaged primary anterior teeth: An in vitro study. Dent Res J (Isfahan) 2015; 12(4): 372-8. [http://dx.doi.org/10.4103/1735-3327.161461] [PMID: 26286271]

[20] Baker LH, Moon P, Mourino AP. Retention of esthetic veneers on primary stainless steel crowns. ASDC J Dent Child 1996; 63(3): $185-9$.

[PMID: 8853822]

[21] Jindal S, Jindal R, Gupta K, Mahajan S, Garg S. Comparative evaluation of the reinforcing effect of different post systems in the restoration of endodontically treated human anterior teeth at two different lengths of post space preparation- an in vitro study. J Dent (Tehran) 2013; 10(2): 124-33. [PMID: 23724211]

[22] Mehrvarzfar P, Rezvani Y, Jalalian E. Comparison of resilon and gutta-percha filling materials on root canal fracture resistance following restoring with quartz fiber posts. J Dent (Tehran) 2012; 9(2): 156-61. [PMID: 23066481]

[23] Scribante A, Massironi S, Pieraccini G, et al. Effects of nanofillers on mechanical properties of fiber-reinforced composites polymerized with light-curing and additional postcuring. J Appl Biomater Funct Mater 2015; 13(3): e296-9.

[http://dx.doi.org/10.5301/jabfm.5000226] [PMID: 26108426]

[24] Teixeira CS, Silva-Sousa YTC, Sousa-Neto MD. Bond strength of fiber posts to weakened roots after resin restoration with different light-curing times. J Endod 2009; 35(7): 1034-9.

[http://dx.doi.org/10.1016/j.joen.2009.04.018] [PMID: 19567329]

[25] Colombo M, Gallo S, Poggio C, Ricaldone V, Arciola CR, Scribante A. New resin-based bulk-fill composites: In vitro evaluation of microhardness and depth of cure as infection risk indexes. Materials (Basel) 2020; 13(6): 1308.

[http://dx.doi.org/10.3390/ma13061308] [PMID: 32183115]

[26] Borges CC, Palma-Dibb RG, Rodrigues FCC, et al. The effect of diode and er, cr: Ysgg lasers on the bond strength of fiber posts. Photobiomodul Photomed Laser Surg 2020; 38(2): 66-74. [http://dx.doi.org/10.1089/photob.2019.4668] [PMID: 31393231]

[27] Hegde J, Ramakrishna KB, Bashetty K, Srirekha, Lekha, Champa An in vitro evaluation of fracture strength of endodontically treated teeth with simulated flared root canals restored with different post and core systems. J Conserv Dent 2012; 15(3): 223-7.

[http://dx.doi.org/10.4103/0972-0707.97942] [PMID: 22876006]

[28] Sharaf AA. The application of fiber core posts in restoring badly destroyed primary incisors. J Clin Pediatr Dent 2002; 26(3): 217-24. [http://dx.doi.org/10.17796/jcpd.26.3.y3660x50n510jv0p] [PMID: 11990042]

[29] Ambica K, Mahendran K, Talwar S, Verma M, Padmini G, Periasamy R. Comparative evaluation of fracture resistance under static and fatigue loading of endodontically treated teeth restored with carbon fiber posts, glass fiber posts, and an experimental dentin post system: an in vitro study. J Endod 2013; 39(1): 96-100.

[http://dx.doi.org/10.1016/j.joen.2012.07.003] [PMID: 23228265]

[30] Judd PL, Kenny DJ, Johnston DH, Yacobi R. Composite resin shortpost technique for primary anterior teeth. J Am Dent Assoc 1990; 120(5): 553-5.

[http://dx.doi.org/10.14219/jada.archive.1990.0071] [PMID: 2186074]

[31] Varvara G, Perinetti G, Di Iorio D, Murmura G, Caputi S. In vitro evaluation of fracture resistance and failure mode of internally restored endodontically treated maxillary incisors with differing heights of residual dentin. J Prosthet Dent 2007; 98(5): 365-72.

[http://dx.doi.org/10.1016/S0022-3913(07)60121-8] 18021825]

[32] Sherfudhin H, Hobeich J, Carvalho CA, Aboushelib MN, Sadig W, Salameh Z. Effect of different ferrule designs on the fracture resistance and failure pattern of endodontically treated teeth restored with fiber posts and all-ceramic crowns. J Appl Oral Sci 2011; 19(1): 28-33. 
[http://dx.doi.org/10.1590/S1678-77572011000100007] [PMID: 21437466]

[33] Gujjar KR, Indushekar KR. Comparison of the retentive strength of 3 different posts in restoring badly broken primary maxillary incisors. $\mathrm{J}$ Dent Child (Chic) 2010; 77(1): 17-24.

[PMID: 20359425]

[34] Heydecke G, Butz F, Hussein A, Strub JR. Fracture strength after dynamic loading of endodontically treated teeth restored with different post-and-core systems. J Prosthet Dent 2002; 87(4): 438-45.

[http://dx.doi.org/10.1067/mpr.2002.123849] [PMID: 12011861]

[35] Pithan S, Vieira RdeS, Chain MC. Tensile bond strength of intracanal posts in primary anterior teeth: an in vitro study. J Clin Pediatr Dent 2002; 27(1): 35-9.

[http://dx.doi.org/10.17796/jcpd.27.1.776566w222426064] [PMID: 12413170]

[36] Pace LL, Hummel SK, Marker VA, Bolouri A. Comparison of the flexural strength of five adhesive resin cements. J Prosthodont 2007; 16(1): $18-24$.
[http://dx.doi.org/10.1111/j.1532-849X.2006.00151.x]

[PMID: 17244303]

[37] Drummond JL, Bapna MS. Static and cyclic loading of fiberreinforced dental resin. Dent Mater 2003; 19(3): 226-31.

[http://dx.doi.org/10.1016/S0109-5641(02)00034-9] [PMID: 12628435]

[38] Mountain G, Wood D, Toumba J. Bite force measurement in children with primary dentition. Int J Paediatr Dent 2011; 21(2): 112-8. [http://dx.doi.org/10.1111/j.1365-263X.2010.01098.x] [PMID: 20731734]

[39] Owais AI, Shaweesh M, Abu Alhaija ES. Maximum occusal bite force for children in different dentition stages. Eur J Orthod 2013; 35(4): 427-33.

[http://dx.doi.org/10.1093/ejo/cjs021] [PMID: 22518063]

[40] Makade CS, Meshram GK, Warhadpande M, Patil PG. A comparative evaluation of fracture resistance of endodontically treated teeth restored with different post core systems - an in-vitro study. J Adv Prosthodont 2011; 3(2): 90-5.

[http://dx.doi.org/10.4047/jap.2011.3.2.90] [PMID: 21814618]

\section{2020 Kadkhodaei et al}

This is an open access article distributed under the terms of the Creative Commons Attribution 4.0 International Public License (CC-BY 4.0), a copy of which is available at: (https://creativecommons.org/licenses/by/4.0/legalcode). This license permits unrestricted use, distribution, and reproduction in any medium, provided the original author and source are credited. 